\title{
Residual Volume and Total Lung Capacity to Assess Reversibility in Obstructive Lung Disease
}

\author{
Conor T McCartney MD, Melissa N Weis MD, Gregg L Ruppel MEd RRT RPFT FAARC, and \\ Ravi P Nayak MD
}

\begin{abstract}
BACKGROUND: Reversibility of obstructive lung disease is traditionally defined by changes in $\mathrm{FEV}_{1}$ or FVC in response to bronchodilators. These may not fully reflect changes due to a reduction in hyperinflation or air-trapping, which have important clinical implications. To date, only a handful of studies have examined bronchodilators' effect on lung volumes. The authors sought to better characterize the response of residual volume and total lung capacity to bronchodilators. METHODS: Responsiveness of residual volume and total lung capacity to bronchodilators was assessed with a retrospective analysis of pulmonary function tests of 965 subjects with obstructive lung disease as defined by the lower limit of normal based on National Health and Nutritional Examination Survey III prediction equations. RESULTS: A statistically significant number of subjects demonstrated response to bronchodilators in their residual volume independent of response defined by FEV 1 or FVC, the American Thoracic Society and European Respiratory Society criteria. Reduced residual volume weakly correlated with response to $F E V_{1}$ and to FVC. No

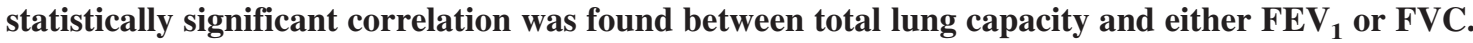
CONCLUSIONS: A significant number of subjects classified as being nonresponsive based on spirometry have reversible residual volumes. Subjects whose residual volumes improve in response to bronchodilators represent an important subgroup of those with obstructive lung disease. The identification of this subgroup better characterizes the heterogeneity of obstructive lung disease. The clinical importance of these findings is unclear but warrants further study. Key words: lung diseases; obstructive; bronchodilator agent; pulmonary disease; chronic obstructive. [Respir Care 2016;61(11):1505-1512. ( 2016 Daedalus Enterprises]
\end{abstract}

\section{Introduction}

Evaluation of obstructive lung disease includes pulmonary function tests with pre- and postbronchodilator measurements. Reversibility in obstructive lung disease is de-

\footnotetext{
Dr McCartney is affiliated with the Department of Internal Medicine as St. Louis University, St. Louis, MO; Dr Weiss and Mr Ruppel and Dr Nayak are affiliated with the Department of Internal Medicine, The Division of Pulmonary, Critical Care and Sleep Medicine, St. Louis, MO.
}

The authors have disclosed no conflicts of interest.

Correspondence: Ravi Nayak MD, 7th Floor Desloge Towers, 3635 Vista Avenue at Grand Boulevard, St. Louis, MO 63110-0250. E-mail: nayakrp@slu.edu.

DOI: $10.4187 /$ respcare. 04323 fined by a change in either $\mathrm{FEV}_{1}$ or FVC. ${ }^{1}$ Many studies focus only on $\mathrm{FEV}_{1}$ as the measure of reversibility, ${ }^{2-8}$ and some have argued that FVC is an underutilized clinical outcome of reversibility. ${ }^{9}$

$\mathrm{FEV}_{1}$ and $\mathrm{FVC}$ are not the only parameters measured in pulmonary function testing that change in response to bronchodilators. Lung volumes have been found to be responsive to bronchodilators independent of $\mathrm{FEV}_{1}{ }^{10-17}$. Lung volumes have the potential to be useful parameters in determining bronchodilator responsiveness, but they are not frequently used. ${ }^{10}$

Lung volumes have important clinical implications. Static hyperinflation is a risk factor for mortality. ${ }^{18} \mathrm{Dy}-$ namic hyperinflation increases the work of breathing ${ }^{19}$ and has elements of reversibility that correlate with inspiratory capacity but not with $\mathrm{FEV}_{1} \cdot{ }^{15,20}$ There is a significant correlation between inspiratory capacity and maximal oxygen consumption. ${ }^{21}$ 
$\mathrm{FEV}_{1}$ has important predictive value regarding symptomatology, frequency of complications, and overall prognosis. ${ }^{4,19} \mathrm{FEV}_{1}$ is the most important tool in assessing obstructive lung disease, but it has limitations: Although $\mathrm{FEV}_{1}$ is a good predictor of mortality, other indices such as walk distance are better predictors. ${ }^{22,23}$

$\mathrm{FEV}_{1}$ responsiveness is not a reliable indicator of increase in exercise tolerance as a response to bronchodilators ${ }^{20,24}$ or improvement in dyspnea. ${ }^{7} \mathrm{FEV}_{1}$ responsiveness has limited value in predicting long-term outcomes, such as hospitalizations and mortality. ${ }^{25,26}$ We hypothesized that there are a significant number of patients whose residual volumes and total lung capacities are bronchodilator-responsive even if their $\mathrm{FEV}_{1}$ or FVC are not.

\section{Methods}

A retrospective analysis of pulmonary function tests was performed for patients who underwent pulmonary function testing between January 1, 2005 and August 31, 2013 at Saint Louis University Hospital (St Louis, Missouri). Subjects 18-79 y old with an $\mathrm{FEV}_{1} / \mathrm{FVC}$ less than the lower limit of normal based on the National Health and Nutrition Education Survey (NHANES) III predicted equation ${ }^{27}$ were included.

Credentialed pulmonary function technologists performed pulmonary function testing. Spirometry and lung volumes by body plethysmography (MCG Diagnostics, St Paul, Minnesota) were performed, according to the 2005 American Thoracic Society and European Respiratory Society (ATS/ERS) recommendations. Subjects withheld bronchodilators for $24 \mathrm{~h}$ before assessment of $\beta$-agonist reversibility. To evaluate reversibility, each subject inhaled 4 puffs of albuterol using a spacer with 30 -s intervals between inhalations. Spirometry was performed $15 \mathrm{~min}$ after bronchodilator administration, followed immediately by measurement of lung volumes. For subjects in whom there were serial tests, only data from their first visits were included.

Subjects were divided into groups based on the degree of obstruction as defined by the 2005 ATS/ERS guidelines. ${ }^{1} \mathrm{FEV}_{1} \geq 70 \%$ was defined as mild obstruction, $\mathrm{FEV}_{1} \geq 60 \%$ but $<70 \%$ as moderate obstruction, $\mathrm{FEV}_{1} \geq$ $50 \%$ but $<60 \%$ as moderately severe obstruction, $\mathrm{FEV}_{1}$ $\geq 35 \%$ but $<50 \%$ as severe obstruction, and $\mathrm{FEV}_{1}<35 \%$ as very severe obstruction. $\mathrm{FVC}, \mathrm{FEV}_{1}$, total lung capacity (TLC), residual volume (RV), and $\mathrm{FEV}_{1} / \mathrm{FVC}$ were analyzed pre- and postbronchodilator using median and interquartile ranges for outcomes in response to bronchodilators by degree of obstruction. A Mann-Whitney U test was performed to determine whether there were statistically significant differences between the degrees of obstruction of each lung volume.

\section{QUICK LOOK}

\section{Current knowledge}

There is disagreement about what constitutes bronchodilator reversibility in pulmonary function testing, but the focus is primarily on $\mathrm{FEV}_{1}$. A small number of studies have looked at other measures of reversibility, such as residual volume (RV) and the RV/TLC ratio.

\section{What this paper contributes to our knowledge}

A sizable number of subjects had a reduction in their RV but did not meet American Thoracic Society criteria for reversibility in bronchodilator testing. The change in $\mathrm{RV}$ cannot be accounted for by change in forced vital capacity.

For $\mathrm{FEV}_{1}$ and $\mathrm{FVC}, 12 \%$ and $200 \mathrm{~mL}$ were used to determine a clinically important response to the bronchodilator per the ATS/ERS criteria. ${ }^{1}$ There is currently no accepted value for clinically important bronchodilator changes for TLC or RV, and various criteria were evaluated to define a clinically important change for the purposes of our study. We attempted to create a threshold at a similar level to the defined standards of $\mathrm{FEV}_{1}$. In our population, the ATS/ERS criterion of $12 \%$ change defining clinically important response was at the 56th percentile in our patient population. Applying this to other lung volumes, the 56th percentile in RV corresponded to an $8 \%$ change in response to bronchodilators; for TLC, it corresponded to $<1 \%$ change.

To further evaluate an appropriate threshold to define clinically important change, we performed receiver operating characteristic (ROC) curves for TLC and RV compared with $\mathrm{FEV}_{1}$ and FVC. For RV, the best ROC curve against $\mathrm{FEV}_{1}$ was generated at $8 \%$, and against $\mathrm{FVC}$ the best ROC was between 8 and 9\%. For TLC, the ROC was not helpful for generating a suggested threshold.

We reviewed coefficients of variation to help decide on various thresholds. Upon reviewing the literature, ${ }^{28}$ we found the coefficient of variation for TLC to be in the range of 2.5-4, suggesting that thresholds of reversibility of 5 and $8 \%$ were reasonable. For RV, a handful of studies reported a coefficient of variation in the range of 6-7, which suggests a cutoff of 12 or $15 \%$. Most of the coefficients of variation for RV were 9-12, and for that reason an RV cutoff of $20 \%$ was used.

Prior studies were reviewed to help select appropriate cutoffs. Most prior studies used a 10\% change in response to bronchodilators as a threshold for clinically important response, ${ }^{11-14,20}$ and therefore this value was also included in our analysis. Twelve percent was also included, because this is the ATS criterion for FEV ${ }_{1}$ and FVC. ${ }^{1}$ In our anal- 
Table 1. Pulmonary Function at Each Degree of Obstruction

\begin{tabular}{|c|c|c|c|c|c|c|}
\hline & $\begin{array}{c}\mathbf{A} \\
\mathrm{FEV}_{1} \geq 70 \%\end{array}$ & $\begin{array}{c}\text { B } \\
60 \% \leq \mathrm{FEV}_{1}<70 \%\end{array}$ & $\begin{array}{c}\mathbf{C} \\
50 \% \leq \mathrm{FEV}_{1}<60 \%\end{array}$ & $\begin{array}{c}\text { D } \\
35 \% \leq \mathrm{FEV}_{1}<50 \%\end{array}$ & $\begin{array}{c}\mathbf{E} \\
\mathrm{FEV}_{1}<35 \%\end{array}$ & $P$ \\
\hline $\mathrm{FEV}_{1}, \%$ predicted & $78.4^{\mathrm{B}, \mathrm{C}, \mathrm{D}, \mathrm{E}}$ & $65.06^{\mathrm{A}, \mathrm{C}, \mathrm{D}, \mathrm{E}}$ & $55.16^{\mathrm{A}, \mathrm{B}, \mathrm{D}, \mathrm{E}}$ & $43.08^{\mathrm{A}, \mathrm{B}, \mathrm{C}, \mathrm{E}}$ & $27.66^{\mathrm{A}, \mathrm{B}, \mathrm{C}, \mathrm{D}}$ & $<.001$ \\
\hline $\mathrm{FEV}_{1}, \%$ change & $6.49^{\mathrm{B}, \mathrm{C}, \mathrm{D}, \mathrm{E}}$ & $8.85^{\mathrm{A}, \mathrm{C}, \mathrm{D}, \mathrm{E}}$ & $11.84^{\mathrm{A}, \mathrm{B}, \mathrm{E}}$ & $12.81^{\mathrm{A}, \mathrm{B}}$ & $15.85^{\mathrm{A}, \mathrm{B}, \mathrm{C}}$ & $<.001$ \\
\hline FVC, $\%$ predicted & $98.15^{\mathrm{B}, \mathrm{C}, \mathrm{D}, \mathrm{E}}$ & $83.00^{\mathrm{A}, \mathrm{C}, \mathrm{D}, \mathrm{E}}$ & $76.60^{\mathrm{A}, \mathrm{B}, \mathrm{D}, \mathrm{E}}$ & $63.68^{\mathrm{A}, \mathrm{B}, \mathrm{C}, \mathrm{E}}$ & $58.96^{\mathrm{A}, \mathrm{B}, \mathrm{C}, \mathrm{D}}$ & $<.001$ \\
\hline FVC, $\%$ change & $3.39^{\mathrm{B}, \mathrm{C}, \mathrm{D}, \mathrm{E}}$ & $5.15^{\mathrm{A}, \mathrm{C}, \mathrm{D}, \mathrm{E}}$ & $6.72^{\mathrm{A}, \mathrm{B}, \mathrm{D}, \mathrm{E}}$ & $9.66^{\mathrm{A}, \mathrm{B}, \mathrm{C}}$ & $12.30^{\mathrm{A}, \mathrm{B}, \mathrm{C}}$ & $<.001$ \\
\hline TLC, $\%$ predicted & $109.52^{\mathrm{B}, \mathrm{C}, \mathrm{D}}$ & $101.80^{\mathrm{A}, \mathrm{E}}$ & $101.95^{\mathrm{A}, \mathrm{E}}$ & $101.11^{\mathrm{A}, \mathrm{E}}$ & $110.63^{\mathrm{B}, \mathrm{C}, \mathrm{D}}$ & $<.001$ \\
\hline TLC, $\%$ change & $0.24^{\mathrm{E}}$ & -0.68 & $-0.82^{\mathrm{E}}$ & -0.46 & $-0.68^{\mathrm{A}, \mathrm{C}}$ & .027 \\
\hline $\mathrm{RV}, \%$ predicted & $131.71^{\mathrm{C}, \mathrm{D}, \mathrm{E}}$ & $140.33^{\mathrm{C}, \mathrm{D}, \mathrm{E}}$ & $150.27^{\mathrm{A}, \mathrm{B}, \mathrm{D}, \mathrm{E}}$ & $161.24^{\mathrm{A}, \mathrm{B}, \mathrm{C}, \mathrm{E}}$ & $201.13^{\mathrm{A}, \mathrm{B}, \mathrm{C}, \mathrm{D}}$ & $<.001$ \\
\hline $\mathrm{RV}, \%$ change & $-5.16^{\mathrm{B}, \mathrm{C}, \mathrm{D}}$ & $-8.27^{\mathrm{A}}$ & $-7.55^{\mathrm{A}}$ & $-7.19^{\mathrm{A}}$ & -4.89 & .10 \\
\hline $\mathrm{FEV}_{1} / \mathrm{FVC}, \%$ predicted & $62.60^{\mathrm{B}, \mathrm{C}, \mathrm{D}, \mathrm{E}}$ & $61.50^{\mathrm{A}, \mathrm{C}, \mathrm{D}, \mathrm{E}}$ & $56.40^{\mathrm{A}, \mathrm{B}, \mathrm{D}, \mathrm{E}}$ & $51.65^{\mathrm{A}, \mathrm{B}, \mathrm{C}, \mathrm{E}}$ & $36.95^{\mathrm{A}, \mathrm{B}, \mathrm{C}, \mathrm{D}}$ & $<.001$ \\
\hline
\end{tabular}

Each lung volume was compared across the 4 degrees of obstruction to determine whether there was a statistically significant difference in lung volumes using a Mann-Whitney U test. Letters listed in superscript above a value indicate a statistically significant difference from subjects with the degree of obstruction corresponding to the column labeled with that letter.

ysis, adding a volume threshold of $200 \mathrm{~mL}$ did not change our number of responders. A threshold of $15 \%$ change was also analyzed, in part because older guidelines suggested a $15 \%$ threshold for FEV 1 and FVC. ${ }^{29}$ Twenty percent was selected for RV because of prior studies. ${ }^{17,30}$ Analyses of both RV and TLC measurements were grouped by degrees of obstruction as defined by ATS/ERS.

The ATS criteria (either FEV 1 or FVC responsiveness) were compared with both total lung capacity and residual volume responsiveness using a chi-square test to assess independence of RV and TLC responsiveness, respectively. A $P$ value of $\leq .05$ was considered statistically significant and therefore represented a response that was independent.

Using Spearman's correlation, scatter plots were created showing the percentage of change in $\mathrm{FEV}_{1}$ correlated to the percentage of change in FVC, RV, and TLC. Similar plots were created to correlate the percentage of change in FVC with the percentage of change of RV and of TLC.

Median and interquartile ranges were used in interpreting the pulmonary function test data in Table 1 rather than mean and SD to better guard against the effects of outliers. This was done because there were a few extreme outliers in our data set that we did not want to exclude, but we also wanted to guard against skewing our data set.

Given the retrospective nature of the data analysis, informed consent was not obtained, because there was no risk to patient well-being. Safeguards were implemented to protect patient data. The Saint Louis University Internal Review Board approved this research project.

\section{Results}

There were 965 subjects, and demographics are shown in Table 2. The population had a slight male predominance, and it was predominantly white.

Table 1 shows the median values and percentage of change in $\mathrm{FEV}_{1}, \mathrm{FVC}, \mathrm{TLC}, \mathrm{RV}$, and the $\mathrm{FEV}_{1} / \mathrm{FVC}$.
Table 2. Baseline Characteristics

\begin{tabular}{lc}
\hline \hline \multicolumn{1}{c}{ Demographics and Baseline Pulmonary Function Tests } \\
\hline Characteristics & $n(\%)$ or Mean \pm SD \\
Sex & \\
$\quad$ Female & $456(47.3)$ \\
Male & $509(52.7)$ \\
Race & \\
Caucasian & $690(71.5)$ \\
Non-Caucasian & $275(28.5)$ \\
Degree of Obstruction by FEV 1 & \\
$>70 \%$ & $195(20.2)$ \\
Between 60\% and 69.9\% & $162(16.8)$ \\
Between 50\% and 59.9\% & $190(19.7)$ \\
Between 35\% and 49.9\% & $262(27.2)$ \\
$<35 \%$ & $156(16.2)$ \\
Age & $59.7 \pm 12.6$ \\
Height $(\mathrm{cm})$ & $167.9 \pm 16.5$ \\
Weight $(\mathrm{kg})$ & $80.1 \pm 22.9$ \\
\hline
\end{tabular}

There is increasing residual volume with worsening obstruction. There was not a consistent difference in TLC with increasing obstruction.

Figure 1A shows the percentage of subjects responsive to bronchodilators as defined by ATS criteria across the ATS-defined subgroups of obstruction. Most subjects who were $\mathrm{FEV}_{1}$-responsive and RV-responsive had moderate, moderately severe, or severe obstruction, and there were fewer responders with either mild or very severe disease. There was increasing FVC response with worsening obstruction, and a similar pattern is seen with ATS criteria.

Figure 1B shows RV responsiveness at different thresholds for percentage change: $8,10,12,15$, and $20 \%$. The higher the threshold for $\mathrm{RV}$ responsiveness used, the fewer patients were responsive. The same pattern persisted across the ATS degrees of obstruction at all thresholds, with most 

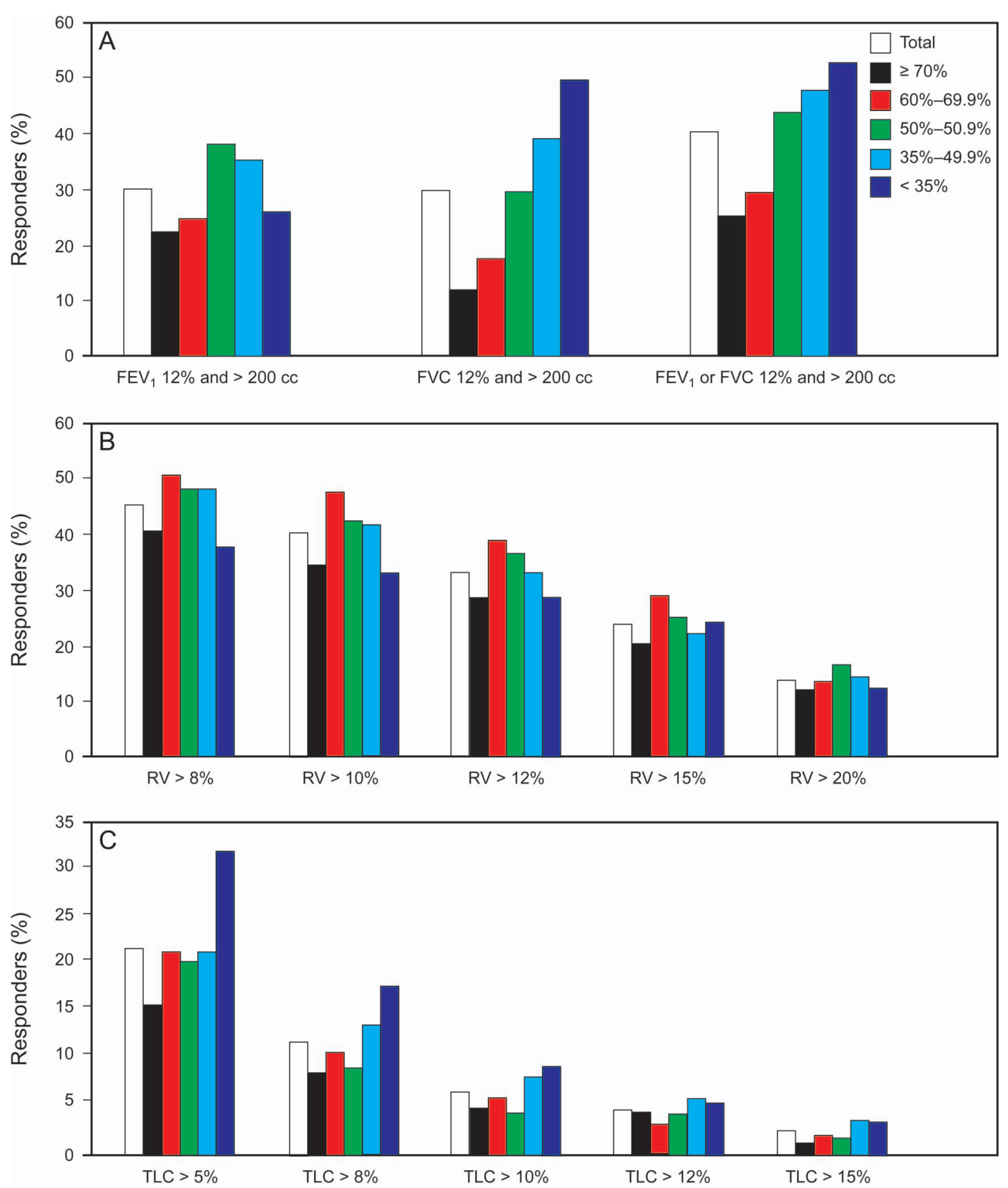

Fig. 1. Responders and degree of obstruction. Percentage of individuals who had a clinical response to bronchodilators by degree of obstruction for FEV $1, F V C$, and ATS criteria (either FEV 1 or FVC). Degree of obstruction was defined by 2005 ATS/ERS criteria with FEV $1 \geq$ $70 \%$ as mild obstruction, $\mathrm{FEV}_{1} \geq 60 \%$ but $<70 \%$ as moderate obstruction, $\mathrm{FEV}_{1} \geq 50 \%$ but $<60 \%$ as moderately severe obstruction, $\mathrm{FEV}_{1} \geq 35 \%$ but $<50 \%$ as severe obstruction and $\mathrm{FEV}_{1}<35 \%$ as very severe obstruction (A). Residual volume (RV) reversibility at different degrees of obstruction percentage of individuals who were RV-responsive at thresholds of $8,10,12,15$, and $20 \%$ reduction of measured lung volumes are shown across the degrees of obstruction as defined by 2005 ATS/ERS criteria (B). Total lung capacity (TLC) reversibility at different degrees of obstruction. Percentage of individuals who were TLC-responsive at thresholds of 5, 8, 10, 12 and $15 \%$ reduction of measured lung volumes are shown across the degrees of obstruction as defined by 2005 ATS/ERS criteria (C).

reversibility present in the intermediate obstruction range and the smallest number of responders at the ends of the spectrum.
Figure 1C shows TLC responsiveness at different thresholds for percentage change: $5,8,10,12$, and $15 \%$. The higher the threshold for TLC responsiveness used the fewer 

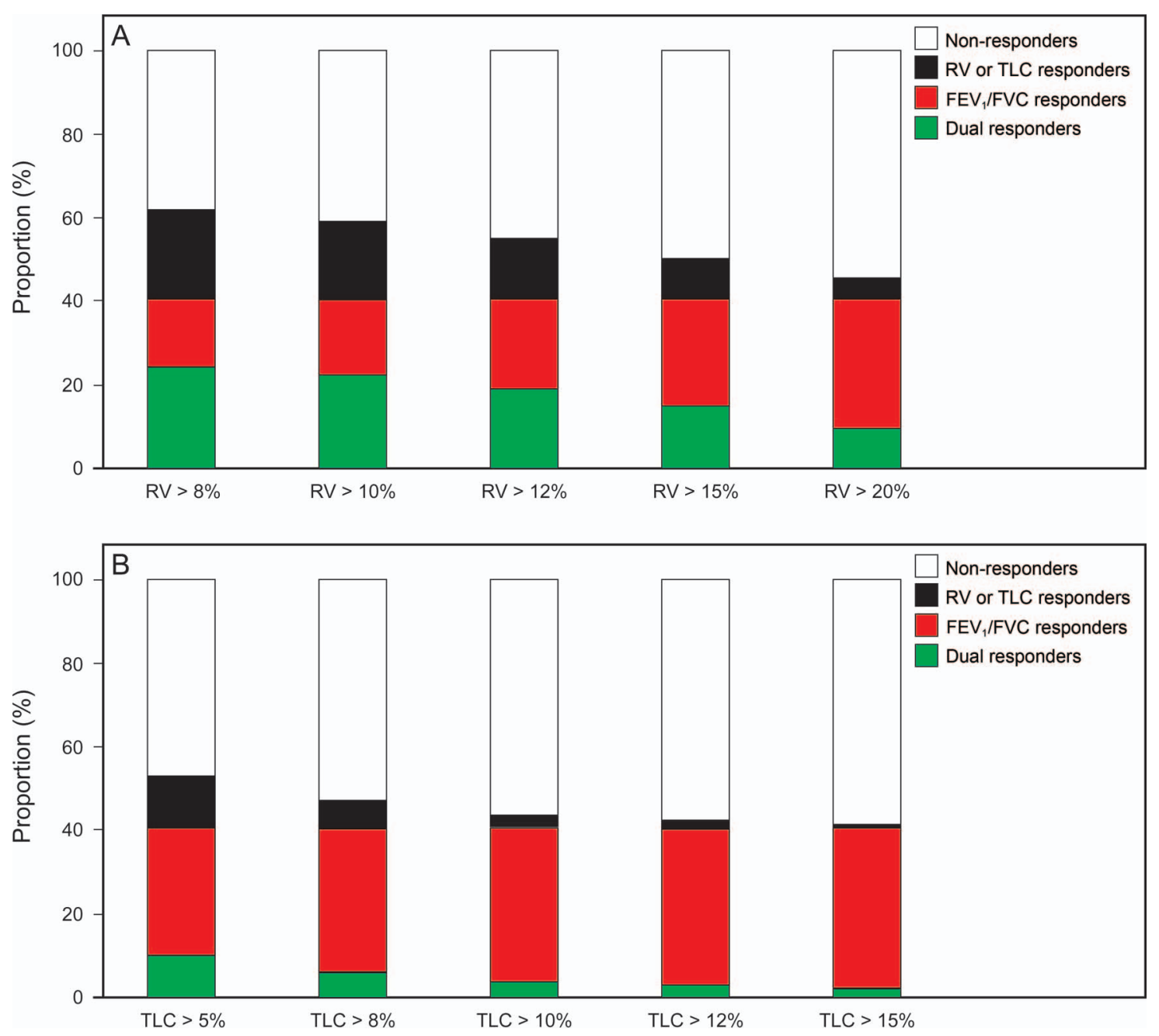

Fig. 2. RV Responsiveness Compared with ATS Criteria. Residual volume (RV) responsiveness and its independence from accepted criteria for responsiveness. The bar graphs show response to bronchodilators for RV alone, dual responders, nonresponders, and responders to ATS criteria (either FEV 1 or FVC). Chi-square testing demonstrates RV response independent of ATS criteria (A). Total lung capacity (TLC) responsiveness, at various thresholds, and its independence from accepted criteria for responsiveness. The bar graphs show response to

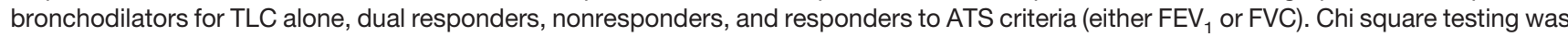
performed to determine whether independence of TLC response was statistically significant (B). $P$-values and the exact numerical values of each response can be found in Table 3.

patients were defined as being responsive. Overall, there is a trend toward a greater TLC response with worsening obstruction.

Figure 2A shows RV responsiveness and its independence from accepted criteria for responsiveness. The subjects were divided into groups based on response to bronchodilators. The groups are those that are RV-responsive only, dual responders, null responders, and responders to ATS criteria (either FEV 1 or FVC). Chi-square testing demonstrates RV response independent of ATS criteria for responsiveness.

Figure 2B shows TLC responsiveness and its independence from accepted criteria for responsiveness. Subjects were divided into 4 groups based on response to bronchodilators. The groups consisted of TLC responsive alone,
Table 3. RV Responsiveness Compared with ATS Criteria

\begin{tabular}{lccccc}
\hline \hline $\begin{array}{c}\text { RV } \\
\text { Threshold }\end{array}$ & $\begin{array}{c}\text { Dual } \\
\text { Responders }\end{array}$ & RV only & ATS only & $\begin{array}{c}\text { Null } \\
\text { Responders }\end{array}$ & $P$ \\
\hline $\mathrm{RV}>8$ & 23.9 & 21.3 & 16.5 & 38.2 & $<.001$ \\
$\mathrm{RV}>10$ & 21.9 & 18.2 & 18.5 & 41.3 & $<.001$ \\
$\mathrm{RV}>12$ & 19.0 & 14.3 & 21.5 & 45.3 & $<.001$ \\
$\mathrm{RV}>15$ & 14.6 & 9.4 & 25.8 & 50.2 & $<.001$ \\
$\mathrm{RV}>20$ & 9.2 & 4.6 & 31.2 & 55 & $<.001$
\end{tabular}

All values are percentages (\%). The patients who are responsive to bronchodilators are shown in this table at increasing thresholds for residual volume (RV) compared with their responsiveness to ATS criteria $\left(\mathrm{FVC}\right.$ or $\left.\mathrm{FEV}_{1}\right)$. The RV threshold is listed in the left most column of each table. Patients fall into 4 categories: dual responders, responders only to RV, responders only to ATS criteria $\left(\mathrm{FEV}_{1}\right.$ or $\left.\mathrm{FVC}\right)$, and null responders. 
Table 4. TLC Responsiveness Compared with ATS Criteria

\begin{tabular}{lccccc}
\hline \hline $\begin{array}{c}\text { TLC } \\
\text { Threshold }\end{array}$ & Dual & TLC only & ATS only & $\begin{array}{c}\text { Null } \\
\text { Responders }\end{array}$ & $P$ \\
\hline TLC $>5$ & 9.3 & 12.1 & 31.1 & 47.5 & .31 \\
TLC $>8$ & 5.3 & 6.3 & 35.1 & 53.3 & .24 \\
TLC $>10$ & 3.2 & 3.1 & 37.2 & 56.5 & .09 \\
TLC $>12$ & 2.6 & 2.0 & 37.8 & 57.6 & .02 \\
TLC $>15$ & 1.6 & 0.7 & 38.9 & 58.9 & .24
\end{tabular}

All values are percentages (\%). The patients who are responsive to bronchodilators are shown in this table at increasing thresholds for total lung capacity (TLC) compared with ATS criteria $\left(\mathrm{FVC}\right.$ or $\left.\mathrm{FEV}_{1}\right)$. A chi-square test was run on each row of the table to test for statistical significance.

dual responders, null responders, and responders based on ATS criteria (either FEV ${ }_{1}$ or FVC). Overall TLC response was very low. The numerical data for Figure $2 \mathrm{~A}$ and $2 \mathrm{~B}$ can be found in Tables 3 and 4 .

There was a strong correlation between $\mathrm{FEV}_{1}$ responsiveness and $\mathrm{FVC}$ responsiveness with an $\mathrm{R}$ value of 0.74 $(P<.001)$. There were weak correlations between $\mathrm{RV}$ responsiveness and that of $\mathrm{FEV}_{1}(\mathrm{R}=-0.28, P<.001)$ or FVC $(\mathrm{R}=-0.301, P<.001)$. There was no correlation in responsiveness between TLC and either $\mathrm{FEV}_{1}(\mathrm{R}=$ $-0.04, P=.24)$ or FVC $(\mathrm{R}=-0.02, P=.48)$.

\section{Discussion}

Obstructive lung diseases are heterogeneous. ${ }^{31}$ Subjects in our population currently classified as having irreversible obstruction by ATS/ERS criteria have reversible residual volumes. This cohort of subjects has been largely neglected in studies of obstructive lung disease. The presence of a weak correlation between RV and $\mathrm{FEV}_{1}$ and between RV and FVC responsiveness suggests a novel group of lung volume responders who are defined as nonresponsive by ATS/ERS criteria, as does the large proportion of subjects who are RV responsive, independent of change in either $\mathrm{FEV}_{1}$ or FVC. It was surprising to find that much of the change in RV could not be accounted for by a change in FVC. Lung volume responders may be part of a clinically important cohort of patients separate from lung volume nonresponders. ${ }^{15,24}$

Most of our population that was RV responsive was in the moderate-severe group of obstruction, and those at the extremes of both mild and very severe obstruction were less RV responsive. This was consistent for RV at all thresholds used to determine a significant change. This contrasts with previous studies that used percentage of predicted lung volumes, ${ }^{11,12}$ which found a positive correlation with the degree of obstruction and the percentage of responders. Using percentage of predicted increases, the number of responders whose obstruction is worse, skews the data toward those with the most air trapping. ${ }^{12}$ This study characterizes percentage of lung volume responders by using change in measured lung volumes rather than percentage of predicted lung volumes.

At the lowest threshold for RV (8\%), 21.3\% of subjects had an RV reduction with nonresponsive spirometry. This represents $35.7 \%$ of subjects currently characterized as being nonresponsive to bronchodilators. At the highest threshold for RV (20\%), 4.6\% of our total patient population had a reduction in RV without significant changes on spirometry. Therefore, $7.7 \%$ of subjects currently characterized as being nonresponsive to bronchodilators have a $>20 \%$ reduction in their residual volume.

The total lung capacity in our cohort showed increasing response with increasing obstruction. TLC was not consistently statistically significant independent of ATS criteria at any threshold.

Lower limit of normal was used for $\mathrm{FEV}_{1} / \mathrm{FVC}$ instead of the Global Initiative for Chronic Obstructive Lung Disease (GOLD) criteria with the intent to minimize falsepositives for obstructive lung disease. ${ }^{32,33}$ GOLD criteria may misclassify healthy elderly patients, because they do not account for the natural fall in $\mathrm{FEV}_{1} / \mathrm{FVC}$ with age. ${ }^{27,34,35}$ A fixed cutoff has increased sensitivity, resulting in patients without symptoms being diagnosed with disease. ${ }^{32,36-38} \mathrm{~A}$ European study of healthy, asymptomatic never-smokers found that $35 \%$ of patients $>70 \mathrm{y}$ old and $50 \%>80$ y old would carry a diagnosis of COPD per GOLD criteria. ${ }^{38}$

Our study made no attempt to remove subjects with an asthma component. Our intent was to include all patients with obstructive disease, as defined by the lower limit of normal based on NHANES III predicted equations. We chose to include subjects with an asthmatic component to avoid eliminating patients with asthma COPD overlap syndrome. ${ }^{39-42}$

Our study is limited by the fact that it is retrospective and from a single clinical center. Reversibility in pulmonary function laboratory testing has limitations in clinical practice. Patients have been shown to benefit clinically from bronchodilators even if their pulmonary function tests do not show a short-term benefit. ${ }^{43,44}$ There is no expectation that a prospective study would alter outcomes of objective numerical data, and it is likely that our data and patient population are generalizable.

The highest percentage of our patient population was severely obstructed, which may reflect a selection bias. This is likely representative of the population at our academic institution. Referral to an academic center for pulmonary function testing is likely to select for more severely diseased patients.

There is selection bias within our patient population, as only subjects' first pulmonary function tests at our institution were included. The first pulmonary test for our 


\section{Lung Volume ReVERSIBILITY}

patients is likely to select for less severe pulmonary function tests; although as we mention, our patients skewed toward the most severely obstructed. A future study could avoid this bias by using a random sample of patients' pulmonary function tests over a time period instead of selecting their first pulmonary function tests.

Choosing a threshold for lung volume responsiveness is difficult. There is no clear consensus on what constitutes reversibility in patients with air-flow obstruction, ${ }^{1,45}$ and reference values are typically derived from healthy subjects using prebronchodilator values. ${ }^{1,46,47}$ This presented a challenge for our study, because we were studying only subjects with airway obstruction as defined by the lower limit of normal. We believe we are able to reasonably justify our thresholds for RV and TLC with our approach of using coefficients of variation and previous studies.

By describing a novel phenotype of residual volume responders, we suggest a new approach in interpreting bronchodilator reversibility that includes RV. Our hope is that this study contributes to a better understanding of how patients respond to bronchodilators. A study of a healthy patient population may be helpful to define a threshold for $\mathrm{RV}$ similar to how $\mathrm{FEV}_{1}$ was defined. ${ }^{47}$

\section{REFERENCES}

1. Pellegrino R, Viegi G, Brusasco V, Crapo RO, Burgos F, Casaburi $\mathrm{R}$, et al. Interpretative strategies for lung function tests. Eur Respir J 2005;26(5):948-968.

2. Barros MJ, Rees PJ. Assessment of reversibility in patients with chronic airflow obstruction. Br J Clin Pract 1992;46(2):132-135.

3. Brand PL, Quanjer PH, Postma DS, Kerstjens HA, Koter GH, Dekhuijzen PN, Sluiter HJ. Interpretation of bronchodilator response in patients with obstructive airways disease. The Dutch Chronic NonSpecific Lung Disease (CNSLD) Study Group. Thorax 1992;47(6): 429-436.

4. Burrows B. An Overview of obstructive lung diseases. Med Clin North Am 1981;65(3):455-471.

5. Clausen JL. The diagnosis of emphysema, chronic bronchitis, and asthma. Clin Chest Med 1990;11(3):405-416.

6. Rodríguez-Carballeira M, Heredia JL, Rué M, Quintana S, Almagro $\mathrm{P}$. The bronchodilator test in chronic obstructive pulmonary disease: interpretation methods. Respir Med 2007;101(1):34-42.

7. Shim C. Response to bronchodilators. Clin Chest Med 1989;10(2): 155-164.

8. Calverley PM, Albert P, Walker PP. Bronchodilator reversibility in chronic obstructive pulmonary disease: use and limitations. Lancet Respir Med 2013;1(7):564-573.

9. Ben Saad H, Préfaut C, Tabka Z, Zbidi A, Hayot M. The forgotten message from gold: FVC is a primary clinical outcome measure of bronchodilator reversibility in COPD. Pul Pharmacol Ther 2008; 21(5):767-773.

10. Manning HL. Bronchodilator therapy in chronic obstructive pulmonary disease. Curr Opin Pulm Med 2000;6(2):99-103.

11. Deesomchok A, Webb KA, Forkert L, Lam YM, Ofir D, Jensen D, O'Donnell DE. Lung hyperinflation and its reversibility in patients with airway obstruction of varying severity. COPD 2010;7(6):428437.

12. Figueroa-Casas JB, Diez AR, Rondelli MP, Figueroa-Casas MP, Figueroa-Casas JC. Assessment of bronchodilator response through changes in lung volumes in chronic airflow obstruction. Medicina (B Aires) 2003;63(5):377-382.

13. O'Donnell DE, Forkert L, Webb KA. Evaluation of bronchodilator responses in patients with "irreversible" emphysema. Eur Respir J 2001;18(6):914-920.

14. Quadrelli SA, Roncoroni AJ, Montiel GC. Evaluation of bronchodilator response in patients with airway obstruction. Respir Med 1999;93(9):630-636.

15. Boni E, Corda L, Franchini D, Chiroli P, Damiani GP, Pini L, et al. Volume effect and exertional dyspnoea after bronchodilator in patients with COPD with and without expiratory flow limitation at rest. Thorax 2002;57(6):528-532.

16. Ramsdell JW, Tisi GM. Determination of bronchodilation in the clinical pulmonary function laboratory. Role of changes in static lung volumes. Chest 1979;76(6):622-628.

17. Newton MF, O'Donnell DE, Forkert L. Response of lung volumes to inhaled salbutamol in a large population of patients with severe hyperinflation. Chest 2002;121(4):1042-1050.

18. Casanova C, Cote C, de Torres JP, Aguirre-Jaime A, Marin JM, Pinto-Plata $\mathrm{V}$, et al. Inspiratory-to-total lung capacity ratio predicts mortality in patients with chronic obstructive pulmonary disease. Am J Respir Crit Care Med 2005;171(6):591-597.

19. Calverley PM. Dynamic hyperinflation: is it worth measuring? Proc Am Thorac Soc 2006;3(3):239-244.

20. O’Donnell DE, Lam M, Webb KA. Spirometric correlates of improvement in exercise performance after anticholinergic therapy in chronic obstructive pulmonary disease. Am J Respir Crit Care Med 1999;160(2):542-549.

21. Díaz O, Villafranca C, Ghezzo H, Borzone G, Leiva A, Milic-Emili $\mathrm{J}$, Lisboa C. Breathing pattern and gas exchange at peak exercise in COPD patients with and without tidal flow limitation at rest. Eur Respir J 2001;17(6):1120-1127.

22. Gerardi DA, Lovett L, Benoit-Connors ML, Reardon JZ, ZuWallack RL. Variables related to increased mortality following out-patient pulmonary rehabilitation. Eur Respir J 1996;9(3):431-435.

23. Pinto-Plata VM, Cote C, Cabral H, Taylor J, Celli BR. The 6-min walk distance: change over time and value as a predictor of survival in severe COPD. Eur Respir J 2004;23(1):28-33.

24. Hatipoglu U, Laghi F, Tobin MJ. Does inhaled albuterol improve diaphragmatic contractility in patients with chronic obstructive pulmonary disease? Am J Respir Crit Care Med 1999;160(6):19161921.

25. Intermittent positive pressure breathing therapy of chronic obstructive pulmonary disease. A clinical trial. Ann Intern Med 1983;99(5): 612-620.

26. Albert P, Agusti A, Edwards L, Tal-Singer R, Yates J, Bakke P, et al. Bronchodilator responsiveness as a phenotypic characteristic of established chronic obstructive pulmonary disease. Thorax 2012; 67(8):701-708.

27. Hankinson JL, Odencrantz JR, Fedan KB. Spirometric reference values from a sample of the general U.S. population. Am J Respir Crit Care Med 1999;159(1):179-187.

28. Hankinson JL, Stocks J, Peslin R. Reproducibility of lung volume measurements. Eur Respir J 1998;11(3):787-790.

29. Criteria for the assessment of reversibility in airways obstruction. Report of the Committee on Emphysema American College of Chest Physicians. Chest 1974;65(5):552-553.

30. Perez T, Chanez P, Dusser D, Devillier P. Prevalence and reversibility of lung hyperinflation in adult asthmatics with poorly controlled disease or significant dyspnea. Allergy 2016;71(1):108-114.

31. Celli BR. The importance of spirometry in COPD and asthma: Effect on approach to management. Chest 2000;117(2 Suppl):15S-19S.

32. Guder G, Brenner S, Angermann C, Ertl G, Held M, Sachs A, et al. "GOLD or lower limit of normal definition? a comparison with 


\section{Lung Volume ReVERSIBILITY}

expert-based diagnosis of chronic obstructive pulmonary disease in a prospective cohort-study". Respir Res 2012;13(1):13.

33. Mohamed Hoesein FA, Zanen P, Lammers JW. Lower limit of normal or FEV1/FVC $<0.70$ in diagnosing COPD: an evidence-based review. Respir Med 2011;105(6):907-915.

34. Enright PL, Kronmal RA, Higgins M, Schenker M, Haponik EF. Spirometry reference values for women and men 65 to 85 years of age. Cardiovascular health study. Am Rev Respir Dis 1993;147(1): 125-133.

35. Crapo RO, Morris AH, Gardner RM. Reference spirometric values using techniques and equipment that meet ATS recommendations. Am Rev Respir Dis 1981;123(6):659-664.

36. Miller MR, Quanjer PH, Swanney MP, Ruppel G, Enright PL. Interpreting lung function data using $80 \%$ predicted and fixed thresholds misclassifies more than 20\% of patients. Chest 2011;139(1):52-59.

37. Swanney MP, Ruppel G, Enright PL, Pedersen OF, Crapo RO, Miller MR, et al. Using the lower limit of normal for the FEV1/FVC ratio reduces the misclassification of airway obstruction. Thorax 2008; 63(12):1046-1051.

38. Hardie JA, Buist AS, Vollmer WM, Ellingsen I, Bakke PS, Morkve $\mathrm{O}$. Risk of over-diagnosis of COPD in asymptomatic elderly neversmokers. Eur Respir J 2002;20(5):1117-1122.

39. de Marco R, Marcon A, Rossi A, Anto JM, Cerveri I, Gislason T, et al. Asthma, COPD and overlap syndrome: a longitudinal study in young European adults. Eur Respir J 2015;46(3):671-679.
40. de Marco R, Pesce G, Marcon A, Accordini S, Antonicelli L, Bugiani $\mathrm{M}$, et al. The coexistence of asthma and chronic obstructive pulmonary disease (COPD): prevalence and risk factors in young, middle-aged and elderly people from the general population. PloS one 2013;8(5):e62985.

41. Gibson PG, McDonald VM. Asthma-COPD overlap 2015: now we are six. Thorax 2015;70(7):683-691.

42. Gibson PG, Simpson JL. The overlap syndrome of asthma and COPD: what are its features and how important is it? Thorax 2009;64(8): 728-735.

43. Tashkin D, Kesten S. Long-term treatment benefits with tiotropium in COPD patients with and without short-term bronchodilator responses. Chest 2003;123(5):1441-1449.

44. O'Donnell DE. Assessment of bronchodilator efficacy in symptomatic COPD: Is spirometry useful? Chest 2000;117(2 suppl):42S-47S

45. Lung function testing: selection of reference values and interpretative strategies. American Thoracic Society. Am Rev Respir Dis 1991; 144(5):1202-1218.

46. Watanabe S, Renzetti AD, Jr., Begin R, Bigler AH. Airway responsiveness to a bronchodilator aerosol. I. Normal human subjects. Am Rev Respir Dis 1974;109(5):530-537.

47. Dales RE, Spitzer WO, Tousignant P, Schechter M, Suissa S. Clinical interpretation of airway response to a bronchodilator. Epidemiologic considerations. Am Rev Respir Dis 1988;138(2):317-320. 